Ho, D. Y. F. (1995). Selfhood and identity in Confucianism, Taoism, Buddhism, and Hinduism: Contrasts With the West. Lournal for the Theory of Social Behaviour, 25 (2), 115-139.

Running head: SELFHOOD AND IDENTITY

Selfhood and Identity in Confucianism, Taoism, Buddhism, and Hinduism: Contrasts With the West

David Y. F. Ho

University of Hong Kong 


\section{Selfhood and I dentity in Confucianism, Taoism, Buddhism, and Hinduism: Contrasts With the West}

Among Western psychologists, the reaction to Eastern ideas of selfhood and identity tends to fall into two extremes. On the one hand, under the pretext of scientism, mainstream psychologists dismiss them as unscientific, to be ignored or at most regarded as an exotic curiosity. On the other hand, a minority do take the Eastern ideas seriously and regard them as a source of inspiration lacking in Western psychology. Dissatisfied with the spiritual emptiness they find in the West, they turn to the East for wisdom and guidance. It seems that a more balanced and critical approach is in order.

In this article, I tread into a territory traditionally shunned by mainstream psychologists: Eastern conceptions of selfhood and identity. The primary reasons are twofold. First, psychologists should no longer remain culturally encapsulated and ignore ideas that have informed selfhood and identity for centuries in the world's most populous communities. Second, through an intellectual journey to the East, we foster a comparative framework that promises a deeper understanding of selfhood and identity and thus an enlargement of our intellectual horizons. This would be a step toward the realization of a psychology of selfhood and identity that acknowledges diverse traditions of both the East and the West.

Many authors tend to speak of the East in global terms, without giving sufficient attention to differences among Asian religiousphilosophical traditions: "Oriental 'philosophy' is, at root, not concerned with conceptions, ideas, opinions, and forms of words at all. It is concerned with a transformation of experience itself" (Watts, 1953, p. 25); Eastern consciousness is characterized by "juxtaposition and identity," in contrast to the Western "unity in diversity" (Haas, 1956); and "Asian theories [of personality] ... emphasize corporate welfare, experiential evidence, intuitive logic, religiophilosophical methods, and subtle indirection in personal relationships" (Pedersen, 1977, p. 367). The distinctiveness of each tradition is lost (see Taylor, 1988, for a discussion of the most common errors of interpretation).

To explore more fully Eastern conceptions of selfhood and identity, I turn to four Asian traditions: Confucianism, Taoism, Buddhism, and Hinduism. The distinction between their philosophical and religious forms of expression is recognized: The philosophical refers to the system of thought contained in a corpus of classical texts or scriptures and subsequent commentaries; the religious refers to a later institutional development, avowed to be built on the philosophical tradition bearing the same name, and is characterized by canonizations, elaboration of rites, and administration by organized clergies.

In present discussion, the focus is placed on the philosophical traditions. The core ideas on selfhood and identity in each tradition 
are explained and examined. I then compare the different Eastern conceptions with one another and with the core of Western conceptions under three headings: (a) subject-object distinction, (b) self-other demarcation and individual identity, and (c) centrality and sovereignty. Psychological decentering is identified as a unifying theme underlying Eastern conceptions of selfhood. Finally, I suggest taking a beginning step toward the reconstruction of selfhood to enlarge our conception of the self and its place in society, nature, and the cosmos.

Confucianism

\section{Four Intellectual Traditions}

Confucianism is, above all, an ethic governing human relationships, of which the most important are the Five Cardinal Relationships:

between ruler and minister, between father and son, between husband and wife, between brothers, and between friends. Essentially, proper conduct means knowing how to act in relation to others. I use the term relationship dominance to capture the essence of social behavior in Confucian societies, in contrast to the Western individualistic pattern. Social actions follow not so much from volition, sentiments, or needs as they do from perceptions of one's relationships with other people. Relationship dominance ascribes primacy to reciprocity, interdependence, and interrelatedness among individuals, not to the individuals themselves. It implies role dominance: To a large extent, the role assumed by the individual, as a minister, parent, spouse, and so forth, overrides his or her personality to determine role behavior. The significance of relationships entails the very definition of identity. Ho (1993) uses the term relational identity to refer to identity defined by a person's significant social relationships.

Closely related with the notion of relational identity is collective identity, wherein an individual's identity is defined by membership in the reference group to which he/she belongs. In the extreme, the individual is not regarded as a separate being, but as a member of the larger whole. For Westerners, an individual's identity may be defined quite independently of the group. For Asians, however, individual identity tends to be interwoven with collective identity. Each member partakes the attributes of the group. Each shares the pride that the group claims, and bears the burden of its collective humiliation. As Lebra (1976) puts it, "Both the pride and the shame of an individual are shared by his group, and in turn the group's pride and shame are shared individually by its members" (p. 36). Lebra refers to the Japanese, but her description applies no less to other Asian peoples governed by Confucianism.

Self psychology provides a language that is remarkably suited to capture the meaning of relational identity. Phenomenologically the definition of identity is reflected in the conception of selfhood. In Confucian cultures, the self is what Ho (1993) calls the relational self, 
one which is intensely aware of the social presence of other human beings. The appearance of others in the phenomenal world is integral to the emergence of selfhood; that is, self and others are conjointly differentiated from the phenomenal world to form the self-in-relationwith-others. This, in short, is the phenomenological representation of selfhood in Confucianism. Such relational nature of selfhood has been recognized by previous authors. Lebra (1976, p. 67) explains that, in Japan, the term for the self is a bun compound noun, jibun; the concept of bun (which means portion, share, part, or fraction) implies an image of society as an organic whole, individuals being parts of that organism. Likewise, Tu (1985, chap. 7) states that Confucian selfhood entails the participation of the other.

Self-cultivation. In Confucian thought, the ultimate purpose of life is self-realization (Tu, 1985, chap. 7). Self-cultivation is essential to fulfilling this purpose and thus occupies a central position in the Confucian conception of selfhood. Despite the centrality of the family in Confucianism, it is not conceived as an end in itself. Rather, it is the natural, necessary, and the most desirable environment for mutual support and personal growth. Self-cultivation is regarded as a necessary condition for familial relationships to be regulated and harmonized. In particular, the father-son relationship, which is absolutely binding, provides a context and an instrumentality for selfcultivation and spiritual development. The filial son, acting according to the ideals embodied in filial piety, maintains a harmonized relationship with his father; his selfhood is thereby realized.

The chun-tzu (man of virtue or noble character; commonly translated as "gentleman" or "superior man") is, above all, a man of self-cultivation. Among the virtues essential for self-cultivation are li (propriety) and cheng (sincerity). The former refers to prescriptive rules for proper conduct; the latter to unwavering devotion to the good. As stated in the Analects (Conversations of Confucius), "To subdue one's self and return to propriety is perfect virtue." And in the Doctrine of the Mean, "The superior man regards the attainment of sincerity as the most excellent thing."

Now in psychological terms, "to subdue one's self" entails impulse control. And in sociological terms, li serves to maintain status hierarchies. As Hsun-tzu states: "Li is that whereby ... love and hate are tempered, whereby joy and anger keep their proper place. It causes the lower orders [of society] to obey, and the upper orders to be illustrious" (translation from Dubs, 1928, pp. 223-224). The prescriptions for impulse control to attain "perfect virtue" are stringent indeed. Confucius commands: "Look not at what is contrary to propriety; listen not to what is contrary to propriety; speak not what is contrary to propriety; make no movement that is contrary to propriety" (Analects). Clearly, self-cultivation in Confucian thought should be differentiated from the notions of self-actualization held by humanistic psychologists in the West. 
A subdued self. The self in Confucianism is a subdued self. It is conditioned to respond to perceptions, not of its own needs and aspirations, but of social requirements and obligations. Incongruence between the inner private self and the outer public self is likely to be present. About the self in Japanese culture, DeVos (1985) concludes: "The Japanese sense of self is directed toward immediate social purposes, not toward a process of separating out and keeping the self somehow distinct, somehow truly individual, as remains the western ideal" ( $p .179$ ). This conclusion applies no less to the Chinese case.

Confucianism has been accused by Chinese intellectuals, especially during the May 4th Movement (a period of intellectual revolt in the early part of the present century in China), of paternalism, conservatism, even oppressiveness. The great emphasis on propriety leaves little room for the unbridled expression of emotions and feelings. The extreme rigidity of prescriptions for proper conduct tolerates no deviation from the norm and thus inhibits the development of individuality. Confucianism tends to produce people who view behavior in terms of whether it meets or fails to meet some external moral or social criteria--and not in terms of individual needs, sentiments, or volition. That is, people who tend to be moralistic, not psychologically minded.

The Confucian ideal of selfhood realized through harmonizing relationships runs afoul of reality in daily life. There is considerable empirical evidence to indicate that, for instance, the Chinese fatherchild relationship tends to be marked by affectional distance, even tension and antagonism (Ho, 1987)--in sharp contrast to the ideal Tu (1985, chap. 7) depicted. Research results are summating to an impressive body of evidence implicating filial piety, a cornerstone in Confucianism, in the development of authoritarian moralism and cognitive conservatism (Ho, 1994b). People endorsing Confucian filial attitudes tend to adopt a passive, uncritical, and uncreative orientation toward learning; to hold fatalistic, superstitious, and stereotypic beliefs; to be authoritarian, dogmatic, and conformist. Parents' attitudes rooted in filial piety tend to result in high rigidity and low cognitive complexity in their children. Thus, the psychological consequences of filial piety would appear to be predominantly negative from the perspective of most contemporary psychologists.

Taoism

Indigenous to China, Taoism represents the Chinese counterculture. Regrettably, it has not received due attention from psychologists. Taoists disdain the Confucian affinity to social convention, hierarchical organization, and governmental rule by the scholar class. To them, the good life is the simple life, spontaneous, in harmony with nature, unencumbered by societal regulation, and free from the desire to achieve social ascendancy--in short, a life lived in accordance with the Tao. Taoists are thus champions of individuality and individual freedom. 
Deceptiveness of language. In Taoism, we find the oldest philosophical expression about the deceptiveness of language. Centuries later, Berkeley argues that words are an impediment to thinking. Taoism predates the philosophy of linguistic analysis of the 20th century. The Tao De Ching (Classic of the Way and of Potency, see Graham, 1989) begins by asserting:

The Way that can be 'Way'-ed

Is not the constant Way.

The name that can be named

Is not the constant name. (p. 219)

The Tao is timeless, all encompassing, yet nameless and indescribable. Any representation of the Tao through language is false: "The knower does not say, the sayer does not know" (Tao De Ching, see Graham, 1989, p. 220). This presents an insurmountable predicament to Taoists: It places them in the awkward position of being unable ever to articulate what the Tao really is. However, being mystics, they are not troubled by this predicament. The point they make is the need to be mindful of the limitation inherent in language. Chuang-tzu's witty aphorisms, anecdotes, and arguments are particularly forceful in inducing skepticism about whether any utterance makes sense at all.

Taoism itself is the embodiment of paradoxes and contradictions. The sage acts without action; and the ruler rules without governing. The intelligent person is like a little child. All things are relative, yet identical because the Tao is unitary. Being and nonbeing produce each other; each derives its meaning from the coexistence of the other. Taoism predates by centuries Derrida's (1978) critique of logocentrism and his deconstructive aim to undo the notions of identity and hierarchy fundamental to Western thought (cf. Graham, 1989; Sampson, 1989).

Selflessness, equalitarianism, and psychological decentering. Taoism disavows a hierarchical view of the self, society, or cosmos. Unlike Confucianism, Taoism does not regard the self as an extension of, and defined by, social relationships. Rather, the self is but one of the countless manifestations of the Tao. It is an extension of the cosmos.

The Tao De Ching speaks of knowing others as being wise, and of knowing one's self as being enlightened. It seems to imply a differentiation between self and others. Yet, the sage has no fixed (personal) ideas, and regards the people's ideas as his own. In Chuang-tzu, regarded as a mystic of unmatched brilliance in China, we find an explicit negation of the centrality of the self: "The perfect man has no self; the spiritual man has no achievement; the true sage has no name" (see de Bary, Chan, \& Watson, 1960, p. 66; also Graham, 1989, p. 193; F. K. Hsu, 1963, p. 394). The ideal is thus selflessness. Yet, the selfless person is not without attributes: He/she becomes a sage in tranquillity, and a king in activity. The selfless person leads a 
balanced life, in harmony with both nature and society. In sum, Chuang-tzu's conception of selfhood entails conscious selftransformation leading to the embodiment of "sageliness within and kingliness without."

It should be emphasized that Chuang-tzu's conception of selflessness does not entail an ontological denial of the self--as in Buddhism, according to which there is no such entity to begin with. Life is not regarded as inherent misery, as in Buddhism; rather, sorrow as well as joy are taken for grant as part of life. Even death is accepted without lamentation, as an integral, though inevitable, part of endless cosmic change. Selflessness is really the philosophical attitude of being identified with the Tao--an attitude that leads to acceptance of both life and death. Further, it encompasses both tranquillity and activity, unlike the Buddhist notion of total quiescence in the state of Nirvana. The selfless person retains human attributes like sageliness and kingliness--unlike the Hindu metaphysical belief that personal identity is totally "lost" with the dissolution of the self in Brahman (cf. Graham, 1989, p. 176, on this point).

When selflessness is attained, the distinction between "I" and "other" disappears. One may then act with complete spontaneity. The mind becomes like a mirror, free from obstinacies and prejudices. Thus one's thinking is to be liberated from not only external social constrictions but also internal psychological impediments. This idea of thought liberation--transcending one's egocentricity--occupies a central place in Chuang-tzu's writings (F. K. Hsu, 1963, pp. 400-405). He states:

To be impartial and nonpartisan; to be compliant and selfless; to

be free from insistence and prejudice; to take things as they

come; to be without worry or care; to accept all and mingle with

all--these were some of the aspects of the system of the Tao

among the ancients.... Their fundamental idea was the equality of all things. They said: ".... The great Tao is all-embracing without making distinctions." (quoted from de Bary et al., 1960, p. 81)

Here is a paradox indeed. Chuang-tzu's assault on analysis ("making distinctions") reflects the power of his own analytic faculty.

As yet, there is virtually no research on the psychological consequences of Taoism. Nonetheless, it seems reasonable to say that psychological decentering and equalitarianism would be fostered. Psychological decentering is implied in the notion of selflessness, the distinction between "I" and "other" being absent (discussed further in the Psychological Decentering subsection below); it follows naturally from the perspective that the individual is humbled in the cosmic scale 
of things. Equalitarianism ascends if no categorical distinctions among people are made, "the equality of all things" being affirmed. Of particular significance is that the relation between men and women is not hierarchical, but complementary. Female imageries are used extensively for cosmic and personal creativity. This is especially remarkable in the patriarchal context of Confucian societies. (See Reed, 1987, for an interesting discussion of women and the use of female imageries in Taoism.)

Buddhism

As in the case of other great traditions, Buddhism has evolved into many sects, each with its own school of thought departing in various ways, sometimes radically, from the teachings of its founder Gautama. Still, at the heart of Buddhism is the metaphysical position that denies the ontological reality of the self. Therefore, to speak of the self in Buddhism is a contradiction in itself. Any construction of the self, including that of the true self in Hinduism, is rejected. From this doctrine of no-self (or no-soul), it follows that the notion of "owning" one's self is nothing but an illusion. Moreover, this illusion, borne of primal ignorance, is the source of suffering; holding onto it is an obsession. Salvation or final deliverance demands ridding oneself of it and terminating the cycle of births and rebirths. Because life is viewed as a condition of inherent degradation and misery, ending the cycle cuts the chain of futility.

If and when moral-intellectual perfection is attained, the illusion of individual self ceases, for there is nothing to be reborn. Nirvana (literally, "blowing out," as of a lamp) is reached. In this state, primal ignorance is extinct, as is the causation for the cycle of births and rebirths. It is a state of absolute, eternal quiescence--a transcendent state of supreme equanimity, beyond the comprehension of ordinary persons unawakened from the illusion of selfhood.

The Buddhist view may be explained with an analogy. An individual candle, when consumed, ceases to be. Yet the light it produced may be transferred to other candles; its "life" continues. A person dies and is truly gone; there remains only the accumulated result of all his/her actions--the karma that will continue to work out its effects on the lives of other sentient beings. Thus, transmigration is really a transfer of karma, not of any individual soul. Reincarnation is really metamorphosis, not metempsychosis: Birth is new birth, not rebirth. The self, then, cannot be an unchanging or permanent individual entity, for there is no life outside the domain of transmigration. Rather, it is a transient flux in the endless process of cosmic changes; for there is nothing eternal or permanent, but change. According to the law of causation in early Buddhism, Interdependent Origination, nothing exists independently of anything else (Stcherbatsky, 1962). The world is thus devoid of independent, substantial, or endurable objects. There is no self, no matter, and no God. Nothing is; everything becomes. Early Buddhism, it may be said, 
has a legitimate claim to be one of the oldest, if not the oldest, "field" (as opposed to "corpuscular") theories of cosmology.

The path to salvation. Having made the diagnosis that holding onto the illusion of individual selfhood is the source of suffering, Buddhism provides a prescription for enlightenment. Self-renunciation holds the key to salvation. Because life is viewed as intrinsically futile, the goal is deliverance from the self, not from worldly sufferings due to social conditions. The ideal to be attained, Nirvana, is a state of transcendence devoid of self-reference. Buddhism has worked out an elaborate system of practice to enable one to attain transcendence. Meditation is an instrumentality central to this system. In a state of transcendent consciousness, the subject-object distinction disappears. Cognition is suspended; the self is absent.

The Buddhist doctrine of salvation, it may be said, is at once the most radical and the most difficult to grasp. Radical because salvation means the end of an illusion--the mirage of phenomenal life. Through supreme effort, the individual has the potential to extinguish the very causation of the continuation of his/her phenomenal life. That is, the individual plays a part in altering the cosmic flow of events, redirecting them onto a path toward the realization of his/her ultimate destiny, Nirvana. Knowledge is power, in the sense that it is the means to uproot the source of misery. Attaining perfect knowledge leads to the extinction of primal ignorance responsible for the causation of births and rebirths.

The doctrine is difficult to grasp because of its paradoxical nature: Individual effort is required; yet, there is no individual agent or self seeking its own salvation at all! The passing stream of events is the only "agent" (Stcherbatsky, 1962, p. 133). Salvation, then, should be thought of as a phenomenon of change in the cosmic scheme of things--not in terms of personal redemption, as in Christianity. But this phenomenon is one that includes conscious self-direction--again, radical.

In later developments, the nature of enlightenment is conceived differently by the Mahayana schools (including Ch'an in China and Zen in Japan). The ideal goal to be reached becomes emptiness, not Nirvana. It is a concept no less difficult to grasp. Emptiness means the mind empty of self and its cravings, but does not mean the nonexistence of the mind. It cannot be understood merely in terms of attaining higher levels of consciousness through meditation merely as a technique devoid of religious-philosophical principles. Rather, it is intertwined with the philosophical doctrine of no-self, which serves to guide meditation. Thus, the selfless-self is integral to the attainment of the mindless-mind--an oxymoron that may approximate a description of the transcendent state of emptiness. In this state, selfhood is absent, cravings are emptied, and enlightened experiencing is no longer impeded. The Buddhist detailed description of successive stages of meditation is distinctive in the psychology of 
consciousness. de Silva (1993) has made a case that Buddhist psychology is relevant and has much to contribute to present-day therapeutic practice.

A comparison with psychoanalysis. The Buddhist path to salvation prescribes ridding oneself of passions and desires, including in particular one's attachment to life. It is based on a total detachment from not only worldly objects but also the ego itself. In the language of psychoanalysis, such detachment may be described as what I call decathexis (not to be confused with anticathexis), the deliberate withdrawal of libido invested in internalized objects and the ego; that is, the destruction of both object cathexis and ego cathexis. As such, it is a demanding--and radical--prescription indeed.

Psychoanalysis has not envisioned, let alone investigated, what the self devoid of all cathexis would be like. It does theorize, however, that in the beginning of life one cannot speak of cathexis, because psychic energy is not yet invested in anything. Before the formation of the ego, mental life is characterized by autistic reality; it is governed solely by the pleasure principle, which functions to render the psychic apparatus as free from excitation as possible. This is called a state of Nirvana, but it should really be distinguished from that of the Buddhist conception. To Freud, Nirvana is an infantile state of precathexis; to Buddhists, it is a state of complete decathexis, desires being extinct, achieved through moral-intellectual perfection only after strenuous personal effort. Nevertheless, the idea of freedom from excitation seems applicable to the Buddhist conception of Nirvana.

It is of interest to add that Freud (1920/1959) links Nirvana to the death instincts: "The dominating tendency of mental life, and perhaps of nervous life in general, is the effort to reduce, to keep constant or to remove internal tension due to stimuli (the 'Nirvana principle') ... and our recognition of that fact is one of our strongest reasons for believing in the existence of death instincts" (p. 98). Given that in Buddhist thought, as far as the individual self is concerned, Nirvana is annihilation, we may ask: Does Buddhism work in the service of the death instincts through speeding the process leading to the state of no-excitation--that is, absolute quiescence? Yet, we must remember that the Buddhist goal is not death; the extinction sought is not life itself, but one's cravings, including that for the continuation of one's life after death.

Hinduism

In Hinduism, the conception of selfhood is strongly informed by monistic metaphysics. This conception is elaborated in Vedanta, one of the major orthodox systems of Indian philosophical thought. In this article, I base the discussion primarily on the Advaita (literally "without a second") school within Vedanta--bearing in mind the need to avoid confusing Vedanta for all of Hinduism. 
The Advaita monistic doctrine states that there is one, and only one, reality, called the Brahman: ubiquitous, absolute, formless, immaterial, immutable, without any attributes, and hence ineffable. The true self, Atman ("breath" or "spirit"), is identical to Brahman. In other words, the Brahman that pervades the universe is found within the individual as well. As pronounced in the Upanishads (classical Indian philosophical treatises contributing to the theology of ancient Hinduism), Brahman is fully contained in the "space within the heart."

Like most other schools of Indian philosophical thought, Vedanta describes the human condition as characterized by suffering, and traces its source to the misconstrued conception of selfhood. Atman appears to be different from Brahman only because of primal ignorance or misconstrual--a failure to discriminate between the true self and the nontrue self. Vedanta provides a simple guideline for making a wise discrimination: The true self is permanent and unchanging; the nontrue self is impermanent and changes continually.

Paranjpe (1988) explains: "To put it in the language of William James, a firm basis for personal identity cannot be found in one's 'empirical selves'--such as the body, material possessions, social roles, or attitudes and images about oneself" (p. 204). That is, James' empirical selves are identified as components of the nontrue self. However, Paranjpe's use of the term personal identity is rather misleading. This is because personal identity belongs to the empirical domain; it is stable over time, but not permanent or unchanging. It has, therefore, nothing to do with the Vedanta permanent true self.

Self-as-knower and self-as-witness. A distinctive Vedanta contribution to the psychology of consciousness is the notion of the self-as-witness. We may recall that Kant (1781/1966) postulated the transcendental ego as the unity of consciousness ("pure original unchangeable consciousness") that precedes all experience and makes experience itself possible. It is also the original and necessary consciousness of self-identity. According to Paranjpe (1988):

The transcendentalism of Vedanta goes a step beyond that of

Kant by postulating an unchanging self-as-witness that underlies the self-as-knower.... the self-as-knower refers to the cognitive

processes whereby innumerable construals are composed, modified, selected, rejected, or blended; the self-as-witness refers to the "blank slate" on which construals are endlessly written,

erased, and rewritten, so to speak. According to Vedanta, this

unchanging ground of knowing is the true self (Atman). (p. 200) The passive, uninvolved self-as-witness must be distinguished from the active ego, which is simultaneously a "knower" that constructs models of the world, an "agent" that plans and executes courses of 
action, and an "enjoyer/sufferer" of the consequences of its actions. The active ego cannot be the true self, because of its continually changing manifestations.

Now, attempting to know the self-as-knower is an intellectual quandary that has bedeviled thinkers since ancient times. In psychoanalytic theory, the self-as-knower (ego) is highly circumscribed in what it "knows." The larger portion of mental life is the unconscious, inaccessible to it. Furthermore, the self-as-knower is mostly unaware of its ignorance. Psychoanalytic therapy is predicated on expanding the self-as-knower: to render more of the unconscious conscious. Psychoanalysis, however, does not address a more fundamental issue. In principle, the self-as-knower cannot be observed because it is the percipient subject, not an object of perception.

The Upanishads realized this predicament, and asked: "With what means could the knower be known?" Centuries later, Brentano (1874/1973) claimed that consciousness is always directed to objects, that is, consciousness of something. Phenomenologists like Husserl (1962) after him have repeated his claim. In contrast, Upanishadic thinkers discovered nonintentional states of consciousness-extraordinary states not characterized by a subject-object split and directedness to objects. They claimed to have reached the unchanging center of awareness, a no-thought zone of consciousness in which the knower and the known become one. If cognition is what links the knower and the known, then this is a transcognitive state in which there is no place for knowledge; as such, it is ineffable.

Accordingly, to know the self-as-witness, the true self, is impossible; it can only be experienced. It is not tabula rasa, like the neonate's blank slate on which no construal has yet been written. To experience the self-as-witness, a purposeful attempt to undo construals already written is necessary. In terms of a metaphor, it is perhaps like erasing temporarily the effects of all previous learning and memory to experience the passive experiencing mind. (Note the parallel with the distinction between precathexis and decathexis in the section on Buddhism above.)

The question arises: Concerning this true self, is it permissible to speak of individual identity at all? That is, can there be individual differences? In principle, the question has no empirical answer, because the nature of Atman is not, and cannot be, cognitively known. There is no way for an individual to compare notes with any other in a manner that would help to answer the question. From the Advaita doctrine it would follow that such individual differences, if they exist at all, can only be different manifestations of the same monistic reality, namely, Brahman. Any belief in an unchanging individual self, as distinct from other unchanging selves, is misconstrued, because it implies the existence of multiple (i.e., nonmonistic) realities. The 
price of realizing true selfhood is the total loss of individual identity, a surrendering of the self to the all-embracing Brahman.

A diagnosis and therapy for the human condition? Paranjpe (1988), a psychologist schooled in both Western and Indian philosophy, claims that Vedanta offers a method to rectify the misconstrued conception, and thereby to restore the self to its true nature--a "diagnosis" of the human condition and a "therapy" to cure it. Vedanta qualifies as a formal theory of personality in terms of the criteria that such a theory "must be stated in an explicit, formal, comprehensive, systematic, and rigorous manner, should be open to experiential verification or empirical testing, and should preferably have practical applications in life" (Paranjpe, 1988, p. 185). Paranjpe has not reported any empirical research conducted, however. And it is fair to ask: If Vedanta does qualify as a personality theory, why has it generated no research?

Paranjpe claims that the conceptual separation of the active ego from the passive self-as-witness has an important existential implication. The separation suggests the possibility of dissociating oneself from ego-involved action, and thus a new mode of being in the world liberated from egoism. Vedanta prescribes a systematic and thorough cognitive deconstruction of the ego, designed to temporarily erase the cognitive construals so that the blank slate of the percipient may be directly experienced in its nascent state. Thus cognitive deconstruction helps to unveil the unchanging true self underlying one's ephemeral psychosocial identity.

Now to experience the blank slate of the percipient in its nascent state, that is, the self-as-witness, is quite a feat. Because the self-aswitness is the true self Atman, which is identical to Brahman, Paranjpe's claim amounts to saying that ultimate reality may be directly experienced through cognitive deconstruction. By analogy, it is like a Christian claiming to experience God directly. Further, a successful deconstruction would logically lead to the realization of the true self, that is, of Atman-Brahman identity. In metaphoric terms, the person has attained the status of being a God-human; the empirical self becomes the Universal Self. Atman-Brahman identity is no longer just a metaphysical belief; it is now reified. A perplexing question then arises: How would one know that one has realized Atman-Brahman identity? And how would others recognize it? The person who believes that he/she has reached it has no means for validation except his/her own experience. This presents a real challenge to others on how to distinguish the true from the false Godhuman, and leaves the person in awkward uncertainty (which may be denied, of course) as to whether his/her belief is or is not a delusion.

In contrast to Paranjpe, Bharati (1985), an anthropologist, says that Advaita monism is intellectually quite simple, despite all claims by pundits to the contrary, and may be stated in a few sentences: 
There is one and only one being in existence.... The multitude of other beings, souls, selves, gods, demons, beasts, stars, and planets, etc., are erroneous superimpositions on the One, the brahman. The task of the wise is to break through this delusion

of multiplicity and to realize his numerical identity with that One. Somehow, the existence of all these other entities must be explained away or, rather, meditated away .... It would be quite silly to state, from a modern philosophical viewpoint, that the idea is either true or false.... and it is only modern Hindus' claim that the teaching is scientific which raises the modern thinker's

ire. (pp. 187-188)

Bharati states that the scholastics of the Hindu tradition were concerned exclusively with the metaphysical Self (capitalized); the empirical self is ignored and denigrated. He makes provocative assertions on how the Advaita doctrine permeates all Hindu values (including the justification of the caste system) and forms the basis for Hindu patterns of thought and behavior. To him, these patterns appear highly inconsistent, if not bizarre or pathological, but they are "normal" in the Hindu cultural context. (He has not put it so directly, but has left no doubt that this is what he wants to convey.) Of course, it is insulting to members of a group to suggest that absurd or abnormal behavior (viewed from the perspective of an outsider) they exhibit is "normal" in their own cultural context! One would question Bharati's characterization of behavioral patterns observed among contemporary Indians. Most of his "data" are anecdotes, or impressionistic observations--filtered and reported through his own biases.

\section{A East-West Comparison}

The East and the West clearly stand in stark contrast against each other in their conceptions of selfhood and identity. Further, the Eastern conceptions differ from those of the West in very different ways as well as among themselves. Confucian selfhood, being anchored in interpersonal relationships, stands apart from those of the other three traditions and is probably more accessible to the Western mind. Western conceptions, of course, do not constitute an undifferentiated whole. However, it is possible to identify the core of the prevailing conceptions.

To sharpen the East-West comparison, I first attempt to characterize briefly the self in the West. Of course, Western conceptions of selfhood and identity, as are the Eastern, are rich in diversity. Still, it is possible to distillate the core common to prevailing Western conceptions (cf. Johnson, 1985; Sampson, 1988, 1989). What emerges is an individualistic self that is intensely aware of itself, its uniqueness, sense of direction, purpose, and volition. It is a center 
of awareness, at the core of the individual's psychological universe. The self is at center stage, and the world is perceived by and through it. Self and nonself are sharply demarcated: The self is an entity distinct from other selves and all other entities. The self "belongs" to the individual and to no other person: The individual feels that he/she has complete and sole ownership of his/her self. It has an identity unique to the individual. The self is sovereign, or at least should have a sense of mastery, in its own household. Having a sense of personal control is essential to selfhood. In a healthy state, the self is stable over time; it is a coherent, integrated, and unitary whole. It is individual, not dividual. Rooted firmly in individualism, the Western self is, in short, the measure of all things.

Sampson (1988) identified three basic psychological dimensions along which psychologies of individualism may be differentiated: the nature of the self-nonself boundary, (b) the understanding of control as personal or field, and (c) the conceptualization of persons as defined by their exclusiveness or their inclusiveness. He distinguished two indigenous psychologies of individualism. One is self-contained individualism, characterized by firm self-nonself boundaries, personal control, and an exclusionary conception of the person or self; this psychology is dominant in U.S. society today. The other is what Sampson terms ensembled individualism, characterized by fluid selfnonself boundaries, field control, and a more inclusive conception of the person; this psychology has greater worldwide presence.

Sampson concluded not only that ensembled individualism can achieve the core cultural ideals of freedom, responsibility, and achievement in a more lasting manner, but also that the self-contained form may actually thwart their realization. Ensembled individualism is clearly more akin to Eastern conceptions of the self.

Underlying Western self-conceptions are presuppositions asserting: (a) a subject-object distinction, (b) a self-other demarcation and individual identity, and (c) the centrality and sovereignty of selfhood. I now explain instances where these presuppositions are negated in Eastern conceptions, and how the negation fosters psychological decentering.

\section{Subject-Object Distinction}

In the Western discourse on selfhood, the subject-object distinction is accepted as given. The term self has come to have two distinct, broad meanings: the self-as-subject (the nominative "I") and the selfas-object (the accusative "me"). To avoid confusion, it would be better to have separate terms for these two meanings. One convention is to use the term ego for the self-as-subject or the selfas-agent, and to reserve the term self to refer to the object of selfperception or self-conception. Thus, the ego is the knower and agent of actions; the self is a self-percept or self-concept--an object known to the knowing ego. However, this convention is by no means 
universally followed. In any case, the self "belongs" to itself (as reflected in the possessive "mine").

Johnson (1985) states: "Self-as-object includes both the idea of self as a social object unto others and that of the self as a social (and psychological) object unto itself" (p. 93). However, a great deal of confusion may be avoided if the object of self-perception and that of other-perception are kept distinct. Self-as-object should be restricted to refer to the object of self-perception or self-conception. It may include one's perception or conception of what others think of oneself, and of what one reveals to others. The object of other-perception pertains to a different concept, namely, face. This concept may be defined in terms of one's social image that is publicly and collectively perceived by others--not necessarily the same image that one reveals to others (Ho, 1994a). Other-perception may include the perception of one's self-perception by others (e.g., what other people think of what one thinks of oneself). In metaphoric terms, self and face are mirror images of each other. (It is unfortunate that psychologists have been obsessed with the self, but have shown little interest in face.)

Implicit in the Western discourse on selfhood, then, is the duality of the self-as-subject and the self-as-object. It leaves unanswered the question of how the self-as-knower may be known (discussed in the section on Hindu selfhood). The issue of subject-object duality is not explicitly addressed in Confucianism. However, duality is implied when Confucius says: "The man of virtue must be watchful over himself when he is alone" (Great Learning). For, this self-monitoring entails both subject (i.e., the watcher) and object (i.e., the watcher being watched).

As to Taoism, the idea of that the Tao is unitary implies a negation of all subject-object distinctions. In his assault on analysis, Chuangtzu is insistent on "the equality of all things." Thinking in terms of dichotomies ("making distinctions") is arbitrary and ultimately futile (for an extended discussion, see Graham, 1989; F. K. Hsu, 1963). In a tale bearing the hallmark of his style, Chuang-tzu relates that once he dreamed he was a butterfly and was happy as a butterfly, not knowing that he was Chuang-tzu. Suddenly he awoke, and was Chuang-tzu again. But he did not know whether it was Chuang-tzu dreaming he was a butterfly or a butterfly dreaming it was Chuang-tzu. Admitting that between Chuang-tzu and the butterfly there must be some distinction, he calls this "the transformation of things"--in the language of the present discourse, a subject-object reversal. The point is that there is no way of answering the question about his/its identity--and no way of knowing whether he was waking or dreaming. From Chuang-tzu's stance, it would follow that framing the question about the self in terms of a subject-object dichotomy leads to nowhere; the question itself has to be questioned. Thinking in terms of such a dichotomy would detract us from spontaneity. Selfless spontaneity 
implies the oneness of subject and object. Through Chuang-tzu's metaphors, we may glimpse at such a state: "mirror things as they are," "losing myself," and "forgetting everything." The sage "uses the eye to look at the eye," has "ears and eyes as images he perceives," and takes his stand "at the ultimate eye."

In contrast to the Western duality, both Buddhist and Hindu conceptions regard the subject-object distinction as an impediment to be overcome--transcended--on the way to higher levels of consciousness. At the heart of Buddhist psychology is the notion of transcendent consciousness. In Western psychological terms, transcendent consciousness is an altered state of consciousness. The term altered suggests that it is not ordinary, everyday experiencing. But the Buddhist enterprise is to seek this very altered state, and to elaborate on how it may be done. The transcendent state has been variously described as "one in which new cognitive relationships are established and where subject-object dichotomies cease" (Rao, 1988, p. 147), and as "the nondual experiencing of existence in which-selfhood being absent--consciousness equals perception without conceptual filtering" (Crook \& Rabgyas, 1988, p. 174). In a similar vein, Vedanta transcendentalism describes the center of awareness as a transcognitive, no-thought zone in which there is no split between the knower and the known (Paranjpe, 1988, p. 202). Self-Other Demarcation and Individual Identity

As Sampson (1988) has argued, the nature of self-nonself boundary is a basic dimension along which different cultural conceptions of the individual may be differentiated. That the self is sharply demarcated from nonself is almost never questioned in Western conceptions. Individual identity is predicated on the development and maintenance of a clear self-other demarcation. Common to all developmental theorists is the thesis that a basic task in development is to ensure the emergence of a distinct sense of self through the processes of separation and individuation. A failure to develop or to maintain self-other boundaries results in a loss of identity, and hence psychopathology. Consequently, to Western psychologists, the ideas of "selflessness" and "no-self" may appear strange, even unpalatable.

The relational self. Markus and Kitayama (1991) state that "many Asian cultures have distinct conceptions of individuality that insists on the fundamental relatedness of individuals to each other" (p. 224). The self is construed as interdependent, not independent as in the West. In East Asia, the dominant ethical system underlying this interdependent construal is Confucianism. The boundary between self and nonself is not sharply demarcated; the self is not distinct and separate from others, encapsulated unto itself. The relational self rooted in Confucianism described by Ho (1993) appears to strike a common chord with expanded conceptions of the self among contemporary Western theorists. Johnson (1985) states, "The self is 
no longer regarded as a unitary phenomenon--that is, as an encapsulated, individual variable. Instead, the self is accepted as an interpersonal, i.e. as an intersubjective, unit" (p. 129).

The importance of relational contexts in the definition of the selfhood has long been recognized in the West; it is, therefore, not unique to Confucian cultures. A fundamental belief in all social sciences is that human character develops only in the social context-clearly a recognition of the crucial role of interpersonal relations in human development. But Confucian conception of social existence goes beyond this belief. Interpersonal relations are of crucial importance not only historically in the formation of human character but also contemporaneously in defining what it means to be human throughout the individual's lifetime. The life of the individual is incomplete! It derives meaning only from the coexistence of other individuals. Without others, the very notion of individual identity loses meaning. In short, the Confucian conception of selfhood is relation centered--in contrast to the individual-centered Western conception.

Confucians do not advocate a dissolution of the self-nonself boundary. They do demand selfhood to be moral and reciprocal. The Confucian self is malleable through education, but it is not mutable. In contrast, the self-other demarcation is negated in the other philosophical traditions. The Taoist self is a part of and in harmony with the cosmos, not distinct, standing apart from, or in opposition to it. This may be one interpretation of what Chuang-tzu meant when he said: "The perfect man has no self." The selfless person thinks of others as "I." Thus, selfhood in Taoism contains both the notions of self-in-other and other-in-self.

In Hinduism, the idea of individuated selfhood is an illusion borne of primal ignorance. If the true self is identical to that unitary, ultimate Brahman, it cannot have an individual identity; it cannot be "owned" by the individual. If there is one, and only one, reality in existence, then in principle there is no distinction to be found between one human and another, between humans and nonhumans, and between life and nonlife. With the final dissolution of the self into Brahman, all illusions of individual identity are obliterated; the ultimate goal of deliverance is reached. The Buddhist doctrine of noself goes to an extreme in denying the very existence of the individual self. All things, including persons, are parts of, and do not exist independently from, an interrelated process of change. Because everything is in perpetual flux, there can be no entity, such as an individual self, that has an unchanging or permanent identity.

The dividual self. That the word individual is derived from the Latin individuus, which means not divisible, illustrates how deeply entrenched is the Western belief in the self as a distinct, holistic entity. The linguistic-intellectual tools Westerners use to reflect on selfhood are a pre-given that predisposes them to think in this way. However, an antithesis to the Western conception--the self as dividual--is found 
in many cultures. In the language of Sampson (1988), the individual self is exclusionary, whereas the dividual self is inclusive.

According to Marriott (1976):

Persons--single actors--are not thought in South Asia to be "individual," that is, indivisible, bounded units, as they are in

much of western social and psychological theory as well as in

common sense. Instead, it appears that persons are generally

thought by South Asians to be "dividual" or divisible. To exist,

dividual persons absorb heterogeneous material influences.

They must also give out from themselves particles of their own coded

substances--essences, residues, or other active influences--that

may then reproduce in others something of the nature of the

persons in whom they have originated. (p. 111)

I find Marriott's assertion an overgeneralization and an

exaggeration. It implies that people in South Asia have a conception of persons that is contrary to common sense. Marriott was describing the conception of a world of fluid, blurred, or permeable boundaries between persons, between the animate and nonanimate, and between humans, gods, spirits, demons, witches, animals, plants, and even inanimate objects. This conception may be found throughout the ages in both the East and the West, as do phenomena such as demonology and exorcism predicated on it.

Nevertheless, in a country like India the fluid boundaries are fully informed by entrenched Hindu beliefs such as karma and reincarnation. The idea of metempsychosis was central to the Pythagoras' school and to the Orphic mysteries in ancient Greece, but it has never pervaded the West to the extent that the belief of reincarnation has in India. Fluid boundaries imply that all things, the self included, are dividual and mutable. Reincarnation is only one of the countless forms of mutation. As F. L. K. Hsu (1963) stated: "Extreme mutability will negate the differences between life and death, between one and many, between men and things, between ego and alter, etc." (p. 175). A question arises: Is magical thinking, at rock bottom, the origin of cultural beliefs in metempsychosis? To put the question differently: To what extent are these beliefs rationalizations and elaborations of magical thinking?

Centrality and Sovereignty

Here, the East-West contrast relates to the dimension of personal control versus field control (Sampson, 1988). Centrality and sovereignty in selfhood are essential to the sense of personal control. 
In contrast, a decentered and dethroned self yields to field control. Eastern conceptions negate the Western centrality and sovereignty of selfhood in different ways. The self is not the measure of all things. Humility rather than a sense of sovereignty is the hallmark of the Eastern ideal.

Relational selfhood in Confucianism takes full recognition of the individual's embeddedness in the social network. The social arena is alive with many actors interacting directly or indirectly with one another in a multiplicity of relationships. It is a dynamic field of forces and counterforces in which the stature and significance of the individual actor appears to be diminished. Yet, selfhood is realized through harmonizing one's relationships with others.

The Taoist conception of self is like a deconstructed Western self. One can hardly fail to discern the parallel between Taoist thought and Derrida's deconstructionism. Derrida's deconstructed self is decentered and multidimensional, rather than integrated and hierarchically arranged; selfhood contains both other-in-self and selfin-other, rather than being an entity set contrastively against other entities (Sampson, 1989). Likewise, the Taoist self is without a center and is not hierarchically organized. It does not have dominion over other creatures, as in Christianity. It does not seek to conquer nature, but to submit to cosmic forces of which it is a part. It does not seek sovereignty, but selflessness--to be at home in the cosmos. In a sense, Taoism is more radical than Derrida's deconstructionism. Chuang-tzu terminates all constructions and deconstructions when he proclaims that "the great Tao is all-embracing without making distinctions." This would be therapeutic to Derrida's obsession with deconstructing the Western tradition, using the intellectual tools coming from that very tradition. No one yet knows, however, what a deconstructed deconstructionism might look like.

The true Buddhist does not seek the realization of selfhood, in this life or hereafter, but attends to the virtue of his/her actions. The selfless-self is the antithesis of the sovereign self. If life is inherently miserable, then why cleave to the mistaken sense of centrality and sovereignty? In Vedanta, the true self to be realized after cognitive deconstruction is the passive, uninvolved self-as-witness, not an active ego with a sense of sovereignty to know, to act, and to enjoy/suffer.

\section{Psychological Decentering}

The Eastern perspectives cannot be characterized by anything short of psychological decentering. They suggest different approaches to decentering, a key to confront the problem of egocentric predicament and thus to rid oneself of prejudices. In Confucianism, the principle of reciprocity (translated as likening-to oneself by Graham, 1989, p. 20) is the most relevant in this regard: It extends the consideration for oneself to the consideration for others. The Confucian Golden Rule states: "The humane man, wishing to establish 
himself, seeks to establish others; wishing to be prominent himself, he helps others to be prominent. To be able to judge others by what is near to ourselves may be called the method of realizing humanity" (Analects). The negative version states: "Do not do to others what you would not want others to do to you" (Analects).

Reciprocity should be distinguished from empathy--which is, in Western psychology, probably the most important construct in the understanding of psychological decentering. In reciprocity, the consideration for others is based on the consideration for oneself. In empathy, it is based on a perception of others' consideration for themselves; the consideration for oneself is suspended. Reciprocity is an extension of one's own self-understanding to understand others. Empathy is understanding others through perceiving the selfunderstanding of others.

If the Confucian prescription for combating egocentricity is not radical enough, the same cannot be said of the other traditions. The concept of selflessness, common to Taoism, Buddhism, and Hinduism, holds the key. To be selfless is to be decentered. And to be decentered is an effective antidote to the cognitive biases of the totalitarian ego described by Greenwald (1980): egocentricity (self as the focus of knowledge), beneffectance (perception of responsibility for desired, but not undesired, outcomes), and cognitive conservatism (resistance to cognitive change).

To Chuang-tzu, the mind of the selfless person is like a mirror. By seeing through all dichotomies, including self and other, one is able to "mirror things as they are." To think of others as "I" may be as close to transcending egocentricity as it is humanly possible. Chuang-tzu says: "Exercise fully what you have received from nature without any subjective viewpoint. In one word, be absolutely vacuous" (quoted from Chan, 1963, p. 207). Here, one can discern the parallel with the stance of universal doubt or epoche (from the Greek epokhe meaning abstention) in Husserl's (1962) reductive phenomenology aimed to avoid all preconceived notions.

The Buddhist renunciation of selfhood aims to destroy the mother of all illusions. Because the illusion of selfhood is the root of egoism, overcoming it brings forth insight into the true nature of things. Like Chuang-tzu, Buddhists use the mirror as a symbol to characterize the mind purified of prejudices. The Vedanta deconstruction of the ego requires a relentless self-examination which involves repeatedly attacking one's dearly held construals of oneself and the world, so as to loosen their grip on the ego (Paranjpe, 1988). As claimed by both Buddhists and Hindus, the transcendent state of consciousness, being transcognitive and hence freed from prejudices, enables one to attain higher or even "perfect" knowledge.

Toward a Reconstruction of Selfhood 
Psychological decentering is thus a unifying theme that highlights the commonality in Eastern conceptions of selfhood and identity. If humility is a hallmark of Eastern selfhood, the four intellectual traditions that have informed it are anything but modest in their goals. Each of these traditions has made superlative claims regarding the realization of selfhood--indeed, of perfection: nobility of moral character through self-cultivation in Confucianism; sageliness within and kingliness without through identifying with the Tao in Taoism; Nirvana through attaining moral-intellectual perfection in Buddhism; and union with the supreme Brahman through destroying primal ignorance in Hinduism. To recapitulate, I summarize the central points in Table 1 to facilitate a comparison of the different traditions on key dimensions.

Yet, in history as in real life today, a very different picture emerges. The historian H. G. Wells (1920) laments the corruption of the Eastern faiths:

The theological disregard of the great Eastern teachers, neither assenting or denying, did ... permit elaborations of explanation and accumulations of ritual from the very beginning.... there was no self-cleansing element in either Buddhism, Taoism, or Confucianism.... The new faiths caught almost every disease of

the corrupt religions they sought to replace; they took over the

idols and the temples, the altars and the censers. (pp. 325-326)

Today the self in Confucian cultures remains subdued, constricted by both external authoritarian sociopolitical institutions and internal psychological dispositions (e.g., authoritarian moralism and cognitive conservatism; see Ho, 1994b). Creativity is stifled. Women are still largely subservient to men. Opposition to oppressive political authority is suppressed, even crushed.

In large measure, religious Taoism and Buddhism have degenerated into materialism and superstition, hopelessly out of touch with their philosophical roots. In funeral rites, self-professed Taoists and Buddhists alike burn fake money to ensure a comfortable "life" for the dead; apparently fearful of hyperinflation in the underworld, hundreds of multimillion-dollar notes are consumed in flames.

Both Buddhism and Hinduism view life as a condition of degradation and misery. Both identified the root of this condition as primal ignorance located within the self, not externally in social conditions. Accordingly, their prescriptions for salvation ignore totally any reference to social change. In early Buddhism, salvation is a personal matter; in later developments, the Mahayana ideal is the selfless devotion to help others by those who have already perfected wisdom and have reached the brink of Nirvana. In Vedanta, the 
metaphysics of Atman-Brahman monism is totally devoid of any reference to the role that others may play in one's salvation. One might ask: If salvation is purely personal, why bother with other people? Would such a doctrine naturally lead to a renunciation of interpersonal involvements and social obligations--that is, to supreme self-centeredness?

In one sense, the Buddhist and Hindu diagnoses of the human condition are correct, given the social conditions of dire poverty and hopelessness that breed degradation and misery. Here, a Marxist interpretation is appealing: Buddhism and Hinduism both represent a "superstructure" dependent on its "economic base." Given that social existence determines consciousness, their psychological views of selfhood reflect defensive responses to appalling external reality. Neither, however, offer anything like a program to change this reality. Socioeconomic conditions in India that gave birth to these two religions have remained debasing to this day.

There is thus occasion to pause for those Westerners who look to the East for a solution to their problems. Yet, the promise of a reconstruction of selfhood informed by the intellectual traditions of the East has too much appeal to be abandoned. Roland (1988), a psychoanalyst, says: "Perhaps we should now add a further blow to the self-esteem of Western man: the realization that the prevailing psychological maps and norms assumed to be universal are in fact Western-centric" (p. xvii). He has embarked on a journey, both literal and figurative, in search of self in India and Japan, and is "convinced that we must speak of three overarching or supraordinate organizations of the self, the familial self, the individualized self, and the spiritual self, as well as an expanding self" (p. 6). The expanding self represents a growing individuation of the self propelled by intercivilizational encounters: "In urban Indians, Japanese, and Americans the expanding self incorporates new organizational structures and paradigms from another civilization, or from certain profound changes generated by their own cultural principles" (pp. 6-7).

To expand our conceptions of selfhood, consider the possibilities of a Confucian relational self without authoritarian and conservative elements; of a Taoist self more faithful to Chuang-tzu's original ideas; a Buddhist self full of wisdom and compassion, without renouncing itself; and a Hindu self ready for creative new construals that include involvement with others and being in the world. Consider too the possibilities of renewed Buddhist and Hindu conceptions of selfhood in which life is affirmed as having intrinsic worth.

Such reconstructions of selfhood, admittedly radical, are at an embryonic stage of development. In time, they will enlarge our horizons, and perhaps even alter fundamentally our views about the self and its place in society, nature, and the cosmos. A needed step in reconstruction is the generation of empirical research guided by conceptual frameworks and methodologies derived from or enriched 
by Eastern intellectual traditions. A daunting task, but not beyond our reach. Psychologists (e.g., Ho, 1993, 1994a, 1994b; Yang, 1993) have already begun exploiting the treasure house of Asian cultures to generate research. Hopefully, this will lead to new knowledge and, more significantly, new avenues for generating knowledge on selfhood and identity. 
References

Brentano, F. (1973). Psychology from an empirical standpoint (2nd ed.). London: Routledge \& Kegan Paul. (Original work published 1874)

Chan, W. T. (Trans. \& Compiler). (1963). A source book in Chinese philosophy. Princeton, NJ: Princeton University Press.

Crook, J., \& Rabgyas, T. (1988). The essential insight: A central theme in the philosophical training of Mahayanist monks. In A. C. Paranjpe, D. Y. F. Ho, \& R. W. Rieber (Eds.), Asian contributions to psychology (pp. 149-183). New York: Praeger.

de Bary, W. T., Chan, W. T., \& Watson, B. (Compilers). (1960). Sources of Chinese tradition (Vol. 1). New York: Columbia University Press.

DeVos, G. (1985). Dimensions of the self in Japanese culture. In A. J. Marsella, G. DeVos, \& F. L. K. Hsu (Eds.), Culture and self: Asian and Western perspectives (pp. 141-184). New York: Tavistock.

Dubs, H. H. (Trans.). (1928). The works of Hsuntze. London: Probsthain.

Freud, S. (1959). Beyond the pleasure principle (J . Strachey, Trans.). New York: Bantam Books. (Original work published 1920)

Graham, A. C. (1989). Disputes of the Tao: Philosophical arguments in ancient China. La Salle, II: Open Court.

Greenwald, A. G. (1980). The totalitarian ego: Fabrication and revision of personal history. American Psychologist, 35, 603-618.

Haas, W. S. (1956). The destiny of the mind: East and West. New York: Macmillan.

Ho, D. Y. F. (1987). Fatherhood in Chinese culture. In M. E. Lamb (Ed.), The father's role: Cross-cultural perspectives (pp. 227-245). Hillsdale, NJ: Erlbaum.

Ho, D. Y. F. (1993). Relational orientation in Asian social psychology. In U. Kim \& J. W. Berry (Eds.), Indigenous psychologies: Research and experience in cultural context (pp. 240-259). Newbury Park, CA: Sage.

Ho, D. Y. F. (1994a). Face dynamics: From conceptualization to measurement. In S. Ting-Toomey (Ed.), The challenge of facework: Cross-cultural and interpersonal variations (pp. 267-284). Albany, NY: SUNY Press.

Ho, D. Y. F. (1994b). Filial piety, authoritarian moralism, and cognitive conservatism. Genetic, Social, and General Psychology Monographs, 120, 347-365.

Hsu, F. K. (1963). [The history of the Chinese philosophy of human nature: The pre-Chin period]. Taichung, Taiwan: Tung Hai University. (In Chinese)

Hsu, F. L. K. (1963). Clan, caste, and club. New York: Van Nostrand/Reinhold.

Husserl, E. (1962). Ideas: General introduction to pure phenomenology (W. R. Gibson, Trans.). New York: Collier Books. 
Johnson, F. (1985). The Western concept of self. In A. J. Marsella, G. DeVos, \& F. L. K. Hsu (Eds.), Culture and Self: Asian and Western perspectives (pp. 91-138). New York: Tavistock.

Kant, I. (1966). Critique of pure reason (F. Max Muller, Trans.). Garden City, NY: Doubleday Anchor Books. (Original work published 1781)

Lebra, T. S. (1976). Lapanese patterns of behavior. Honolulu: The University Press of Hawaii.

Markus, H. R., \& Kitayama, S. (1991). Culture and the self: Implications for cognition, emotion, and motivation. Psychological Review, 98, 224-253.

Marriott, McK. (1976). Hindu transactions: Diversity without dualism. In B. Kapferer (Ed.), Transaction and meaning: Directions in the anthropology of exchange and symbolic behavior. Philadelphia: Institute for the Study of Human Issues.

Paranjpe, A. C. (1988). A personality theory according to Vedanta. In A. C. Paranjpe, D. Y. F. Ho, \& R. W. Rieber (Eds.), Asian contributions to psychology (pp. 185-213). New York: Praeger.

Pedersen, P. B. (1977). Asian personality theory. In R. J. Corsini (Ed.), Current personality theories (pp. 367-397). I tasca, II: Peacock.

Rao, K. R. (1988). Psychology of transcendence: A study of early Buddhistic psychology. In A. C. Paranjpe, D. Y. F. Ho, \& R. W. Rieber (Eds.), Asian contributions to psychology (pp. 123-148). New York: Praeger.

Reed, B. E. (1987). Taoism. In A. Sharma (Ed.), Women in world religions (pp. 161-181). Albany: State University of New York Press.

Roland, A. (1988). In search of self in India and Japan: Toward a cross-cultural psychology. Princeton: Princeton University Press.

Sampson, E. E. (1988). The debate on individualism. American Psychologist, 43, 15-22.

Sampson, E. E. (1989). The deconstruction of the self. In J . Shotter \& K. J. Gergen (Eds.), Texts of identity (pp. 1-19). Newbury Park, CA: Sage.

Stcherbatsky, F. T. (1960). Buddhist logic (Vols. 1-2). New York: Dover. (Original work published circa 1930)

Taylor, E. (1988). Contemporary interest in classical Eastern psychology. In A. C. Paranjpe, D. Y. F. Ho, \& R. W. Rieber (Eds.), Asian contributions to psychology (pp. 79-119)). New York: Praeger.

Tu, W. M. (1985). Confucian thought: Selfhood as creative transformation. Albany, NY: State University New York Press.

Watts, A. W. ((1953). Asian psychology and modern psychiatry. American Journal of Psychoanalysis, 13, 25-30..

Wells, H. G. (1920). The outline of history: Being a plain history of life and mankind. New York: Garden City Books.

Yang, K. S. (Ed.) (1993). The commencement and development of indigenous psychology. [Indigenous Psychological Research in Chinese Societies], No. 1. (In Chinese) 


\section{Author Note}

The author gratefully acknowledges the financial support to the present study from the University of Hong Kong.

Correspondence concerning this article should be addressed to David Y. F. Ho, Department of Psychology, University of Hong Kong, Hong Kong. 
Table 1.

Central Positions of Different Traditions on Key Dimensions.

\begin{tabular}{|c|c|c|c|c|}
\hline Dimension & Confucianism & Taoism & Buddhism & Hinduism \\
\hline | deal & $\begin{array}{l}\text { nobility of moral } \\
\text { character } \\
\text { through self- } \\
\text { cultivation }\end{array}$ & $\begin{array}{l}\text { sageliness } \\
\text { within and } \\
\text { kingliness } \\
\text { without through } \\
\text { identifying with } \\
\text { the Tao }\end{array}$ & $\begin{array}{l}\text { Nirvana through } \\
\text { attaining } \\
\text { perfect moral- } \\
\text { intellectual } \\
\text { knowledge }\end{array}$ & $\begin{array}{l}\text { union with } \\
\text { Brahman } \\
\text { through } \\
\text { destroying } \\
\text { primal } \\
\text { ignorance }\end{array}$ \\
\hline $\begin{array}{l}\text { Subject- } \\
\text { object } \\
\text { distinction }\end{array}$ & $\begin{array}{l}\text { distinction } \\
\text { implied in } \\
\text { private self- } \\
\text { examination }\end{array}$ & $\begin{array}{l}\text { negation of } \\
\text { duality implied } \\
\text { in the oneness } \\
\text { of the Tao }\end{array}$ & $\begin{array}{l}\text { transcended; } \\
\text { nondual } \\
\text { experiencing }\end{array}$ & $\begin{array}{l}\text { transcended; } \\
\text { split betweer } \\
\text { the knower a } \\
\text { the known }\end{array}$ \\
\hline $\begin{array}{l}\text { Self-other } \\
\text { demarcation } \\
\text { and individual } \\
\text { identity }\end{array}$ & $\begin{array}{l}\text { relational self; } \\
\text { dissolution of } \\
\text { the self-nonself } \\
\text { boundary not } \\
\text { advocated }\end{array}$ & $\begin{array}{l}\text { demarcation } \\
\text { negated; think } \\
\text { of others as "I"; } \\
\text { champions } \\
\text { individuality }\end{array}$ & $\begin{array}{l}\text { negated; } \\
\text { doctrine of no- } \\
\text { self denies the } \\
\text { existence of the } \\
\text { individual self }\end{array}$ & $\begin{array}{l}\text { negated; } \\
\text { individual } \\
\text { identity } \\
\text { obliterated ir } \\
\text { Atman- } \\
\text { Brahman }\end{array}$ \\
\hline $\begin{array}{l}\text { Centrality } \\
\text { and } \\
\text { sovereignty }\end{array}$ & $\begin{array}{l}\text { decentered; } \\
\text { yields to field } \\
\text { control }\end{array}$ & $\begin{array}{l}\text { decentered; the } \\
\text { self is not } \\
\text { hierarchically } \\
\text { organized }\end{array}$ & $\begin{array}{l}\text { decentered; } \\
\text { selfless-self }\end{array}$ & $\begin{array}{l}\text { decentered; } \\
\text { true self is th } \\
\text { passive, } \\
\text { uninvolved s } \\
\text { as-witness }\end{array}$ \\
\hline $\begin{array}{l}\text { Psychological } \\
\text { decentering }\end{array}$ & $\begin{array}{l}\text { principle of } \\
\text { reciprocity }\end{array}$ & selflessness & $\begin{array}{l}\text { renunciation of } \\
\text { selfhood }\end{array}$ & $\begin{array}{l}\text { deconstructic } \\
\text { of the ego }\end{array}$ \\
\hline
\end{tabular}

